\title{
Correction to: A Predictive Model of High Shear Thrombus Growth
}

\author{
Marmar Mehrabadi, Lauren D. C. Casa, Cyrus K. Aidun, and David N. Ku \\ George W. Woodruff School of Mechanical Engineering, Georgia Institute of Technology, Atlanta, GA 30332, USA
}

\section{Correction to: Annals of Biomedical Engineering (2016) https://doi.org/10.1007/s10439-016-1550-5}

This erratum is to correct the heading of column 2 (titled "b") in Table 1, which was missing proper units. The heading for that column was revised to include proper units, reading " $\mathrm{b}\left(\times 10^{-6} \mathrm{~s}\right)$ ".
Publisher's Note Springer Nature remains neutral with regard to jurisdictional claims in published maps and institutional affiliations.

Address correspondence to David N. Ku, George W. Woodruff School of Mechanical Engineering, Georgia Institute of Technology, Atlanta, GA 30332, USA. Electronic mail: david.ku@me.gatech.edu

The original article can be found online at https://doi.org/10. 1007/s10439-016-1550-5. 